\title{
Memory Property of Grey Accumulation Generation Sequence
}

\author{
Lifeng Wu $\mathbb{D}$, Xiaohui Gao, and Yan Chen $\mathbb{D}$ \\ College of Economics and Management, Hebei University of Engineering, Handan 056038, China \\ Correspondence should be addressed to Yan Chen; 964129856@qq.com
}

Received 24 March 2019; Revised 16 May 2019; Accepted 10 June 2019; Published 1 July 2019

Guest Editor: Murari Andrea

Copyright (c) 2019 Lifeng Wu et al. This is an open access article distributed under the Creative Commons Attribution License, which permits unrestricted use, distribution, and reproduction in any medium, provided the original work is properly cited.

\begin{abstract}
The influence of grey accumulation generation operator on the memory of time sequence is discussed. Generalized Hurst exponent (GHE) approach is used to calculate the memory in three cases, namely, the M3-Competition data, the air quality index in Beijing, Xingtai, and Handan, and the power generating capacity, and car production index in Hebei province. The result indicates that one order accumulation generation operator (1-AGO) can weaken the volatility and strengthen the memory of time sequence. It also explains the reason that one-order accumulation can be used in grey prediction.
\end{abstract}

\section{Introduction}

Since the introduction of grey prediction theory, it is has been widely applied in many fields, such as Beijing's tertiary industry [1], natural gas demand in China [2], return flow of end-of-life vehicles [3], etc. Typically, a novel multivariable grey forecasting model was proposed to forecast the number of motor vehicles in Beijing [4]. By using a self-adapting intelligent grey model, the forecasting results were substantially improved [5]. A grey model, based on a data grouping approach, was used to predict quarterly hydropower production in China [6]. The nonlinear grey multivariable model was supposed to be potentially suitable for forecasting carbon emissions due to fossil energy consumption [7]. To explore the factors causing smog weather, the grey dynamic trend incidence model was developed [8]. The grey prediction model with a nonlinear optimized time response method was presented to forecast electricity consumption in China [9].

The AGO can change the process from grey to white. It also occupies an extremely important position in the grey system theory [10]. It can reveal the patterns (laws) in chaotic original data and smooth the irregularities in the raw data. Therefore, the AGO is an indispensable part of grey forecasting [11]. To enhance the prediction accuracy, many scholars have made significance contribution to the problem. Using the local sequence grey accumulation, the forecasting accuracy can be improved to some degree [12]. The seasonal rolling grey forecasting model with a cycle truncation AGO is a complement to grey prediction [13]. The fractional-order accumulation can reduce errors from the inverse AGO of the grey model [14]. However, no study has been conducted to determine whether the grey AGO can change the memory of time sequence. Because the Hurst exponent can represent the memory of time sequence, the GHE is utilized to estimate the memory in this paper. The influence of the AGO on the memory of time sequence is analyzed through a series of experimental cases.

The rest of this paper is organized as follows. The proposed calculation method is described in Section 2. The three experimental cases are detailed in Section 3. The comparison of first-order single variable grey forecasting model and other models is shown in Section 4. The conclusion is presented in Section 5.

\section{Method}

The GHE was presented to calculate the memory [15]. It is defined as

$$
k_{q}(\tau)=\sum_{t=0}^{T-\tau} \frac{|X(t+\tau)-X(t)|^{q}}{T-\tau+1}
$$

where $T$ is the length of time sequence $X(t)$ and $k_{q}(\tau)$ is the statistic. Equation (1) can yield a series of values by changing 
the value of $\tau$. The relationship between $k_{q}(\tau)$ and $\tau$ can be described as follows:

$$
k_{q}(\tau) \propto \tau^{q H(q)}
$$

Thus, we can estimate the Hurst exponent of time sequence in (1)-(2) for $q=2$. When $0 \leq H<0.5$, the time sequence reveals its antipersistence. In addition, the closer $\mathrm{H}$ to 0 , the greater intensity of this antipersistence behavior [16]. When $H=0.5$, the time sequence follows a random walk [1722]. When $0.5<H<1$, the time sequence implies strong persistence. When $H=1$, the tendency of future can be predicted by current state [23].

The process of estimation the Hurst exponent $H(2)$ is shown as follows.

Step 1. For positive time sequence $X=\left\{x^{(0)}(1), x^{(0)}(2)\right.$, $\left.\cdots x^{(0)}(n)\right\}$, the one-order accumulation of the time sequence can be obtained by

$$
X^{(1)}(t)=\sum_{j=1}^{t} x^{(0)}(j), \quad t=\{1,2, \cdots n\}
$$

Equation (3) is called the 1-AGO.

Step 2. Calculate a series of $K_{2}(\tau)$ by using the following:

$$
k_{2}(\tau)=\sum_{t=0}^{T-\tau} \frac{\left|X^{(1)}(t+\tau)-X^{(1)}(t)\right|^{2}}{T-\tau+1}, \quad 3 \leq \tau \leq \frac{T}{2}
$$

Step 3. According to the formula, we have

$$
k_{2}(\tau) \propto \tau^{2 H(2)}
$$

The least-square method is utilized to estimate the Hurst exponent $H(2)$.

\section{Experiments and Analysis}

All the experiments in this study were conducted by using the software R i386 3.4.1. The Hurst exponent values and the corresponding analyses of three cases are described in detail below.

Case 1. The data are from the M3-Competition (N2831, $\mathrm{N} 2832$, and N2833) and are downloaded from the Internet site: https://cran.r-project.org/web/packages/Mcomp/. The one-order accumulation sequence is presented in Figure 1. The Hurst exponent value of three groups of data is given in Table 1. The memory of three groups of data is shown in Figure 2.

In Figure 1, the original data from N2831 to N2833 have different distribution and strong randomness. However, oneorder accumulation sequence from N2831 to N2833 nearly distributes in a straight line; it implied that one-order accumulation sequence has substantial developing tendency and stronger regularity.

As shown in Table 1, the $H(2)$ values of the original sequence are less than 0.5 ; this indicated that the original
TABLE 1: The Hurst exponent value of three groups of data.

\begin{tabular}{lccc}
\hline & $\mathrm{N} 2831$ & $\mathrm{~N} 2832$ & $\mathrm{~N} 2833$ \\
\hline Original sequence & 0.08 & 0.02 & 0.08 \\
Accumulation sequence & 0.99 & 0.94 & 0.98 \\
\hline
\end{tabular}

time sequence reveals its antipersistence. In contrast, the $H(2)$ values of accumulation sequence are all larger than 0.90; it implied that the memory of time sequence can be strengthened and the randomness of the time sequence can be weakened by AGO.

It can be noted in Figure 2 that the accumulation sequence of time sequence is regularly distributed in a straight line. The $H(2)$ value of accumulation sequence is larger than that of the original time sequence.

Case 2. Beijing, Handan, and Xingtai are the three cities selected for comparison, where the air is seriously polluted. The air quality index (AQI) data are collected from http://www.zhb.gov.cn/. Since 2013, the air pollution has been noticed by citizens. The government has took urgent measures to control this situation. The result of $H(2)$ in the three cities is in Table 2. The AQI of Beijing, Handan, and Xingtai from 2014 to 2016 are given in Figure 3. The memory results of the three group data are plotted respectively in Figure 4.

It can be seen in Figure 3 that the AQI values in winter are higher than that of in the other seasons. In this situation, the AQI time sequence in Beijing, Handan, and Xingtai has fluctuated randomly. However, one-order accumulation of AQI has stronger regularity. It is possible to establish a suitable model.

As can be seen in Table 2, the $H(2)$ values of the original sequence are all close to 0 ; it implied that the original $\mathrm{AQI}$ time sequence have quite strong antipersistence and mutability. However, the $H(2)$ values of the accumulation sequence are all close to 1.0; it indicated that the accumulation AQI time sequence has higher regularity. Consequently, it can be more extensively applied for prediction in various fields.

It is observed in Figure 4 that the original AQI sequence is disperse randomly while the accumulation sequence is regularly distributed in a straight line; it revealed that the $H(2)$ value of the accumulation sequence is larger than that of the original time sequence.

Case 3. Hebei province is located in the North China Plain. Its power generating capacity and car production index are considered to analyze the memory. These data are collected from National Bureau of Statistics of China. The $H(2)$ values of the two industry indexes in Hebei province are listed in Table 3. The original value and one-order accumulation value of two indexes are presented in Figure 5. The memory results of two indexes in Hebei province are plotted in Figure 6.

It is implied that the tendency of both indexes are increasing slightly in Figure 5. Furthermore, one-order accumulation sequence of both indexes has strong regularity. It is clear that the trend of on- order accumulation sequence is more obvious than the original sequence. 


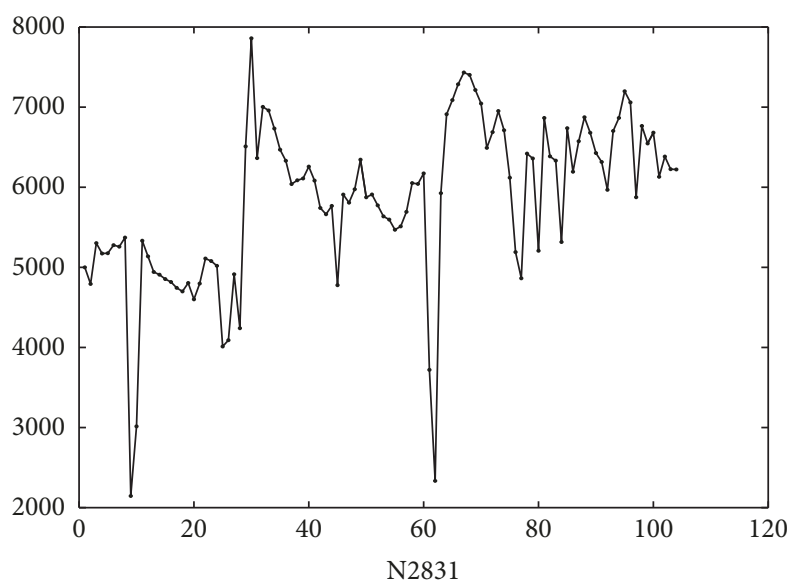

(a) The original value of $\mathrm{N} 2831$

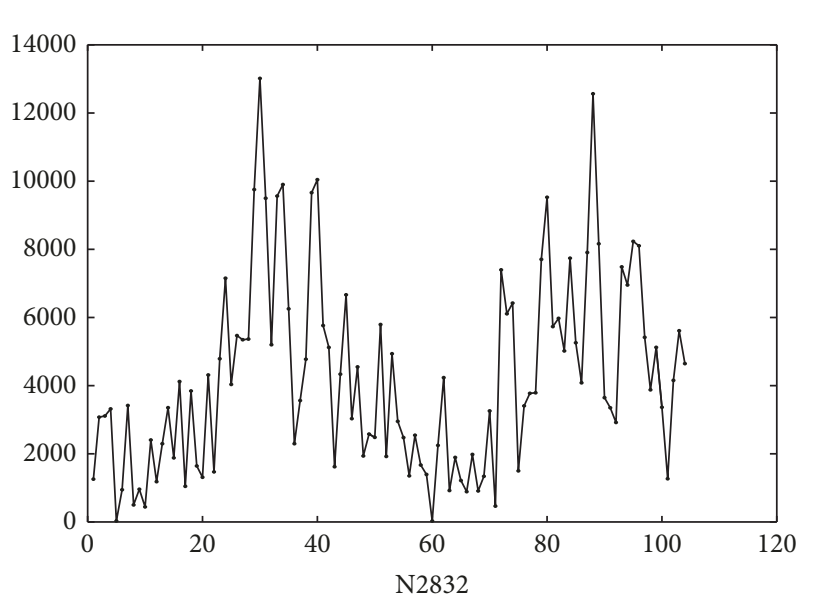

(c) The original value of N2832

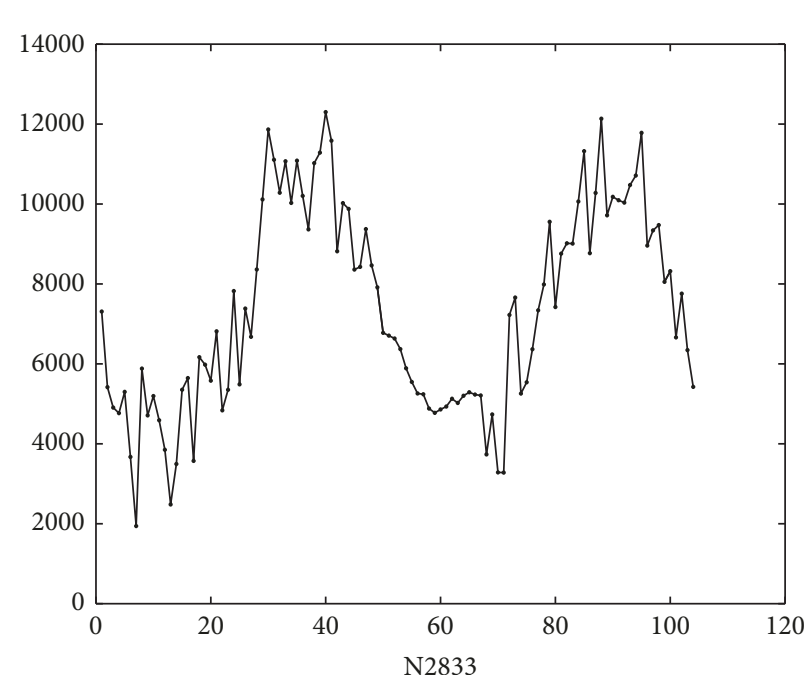

(e) The original value of $\mathrm{N} 2833$

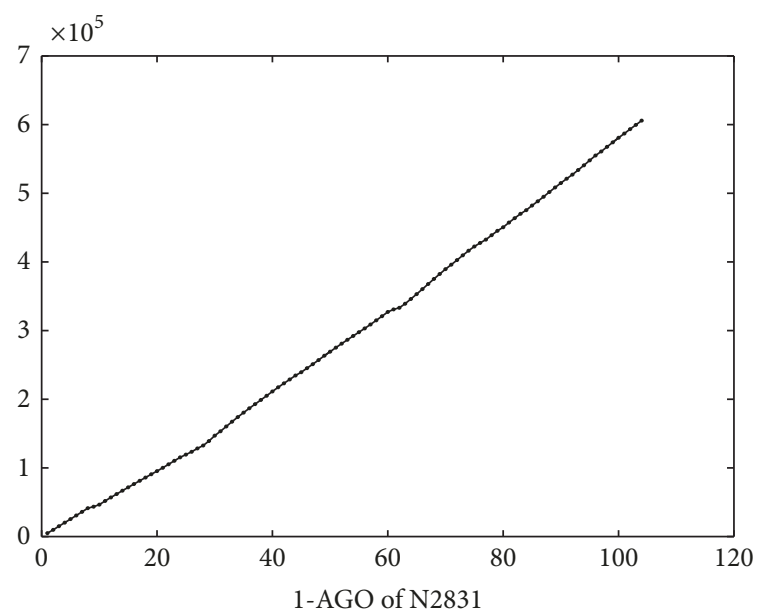

(b) The 1-AGO of N2831

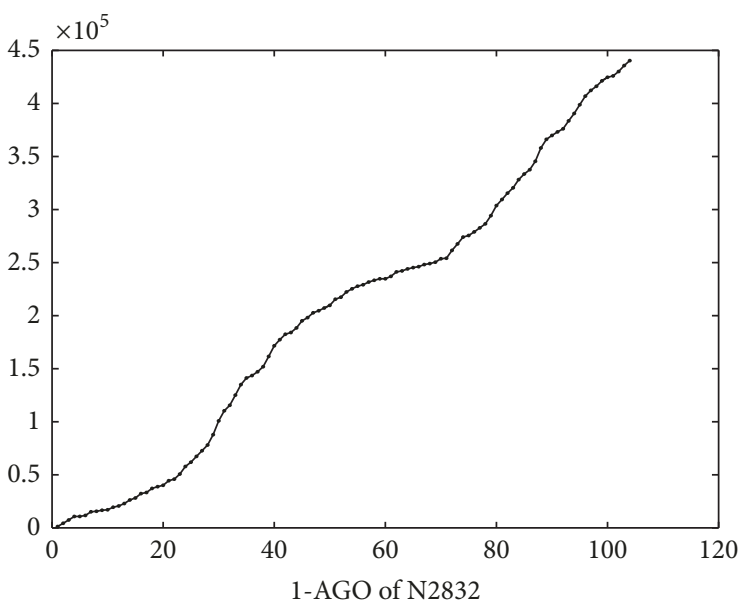

(d) The 1-AGO of N2832

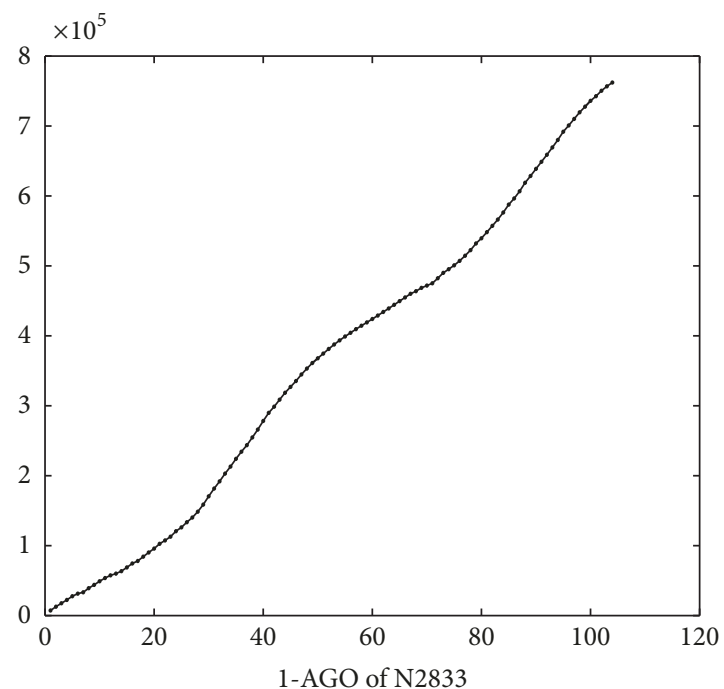

(f) The 1-AGO of N2832

FIgURE 1: The original value and one order accumulation value of three groups data. 


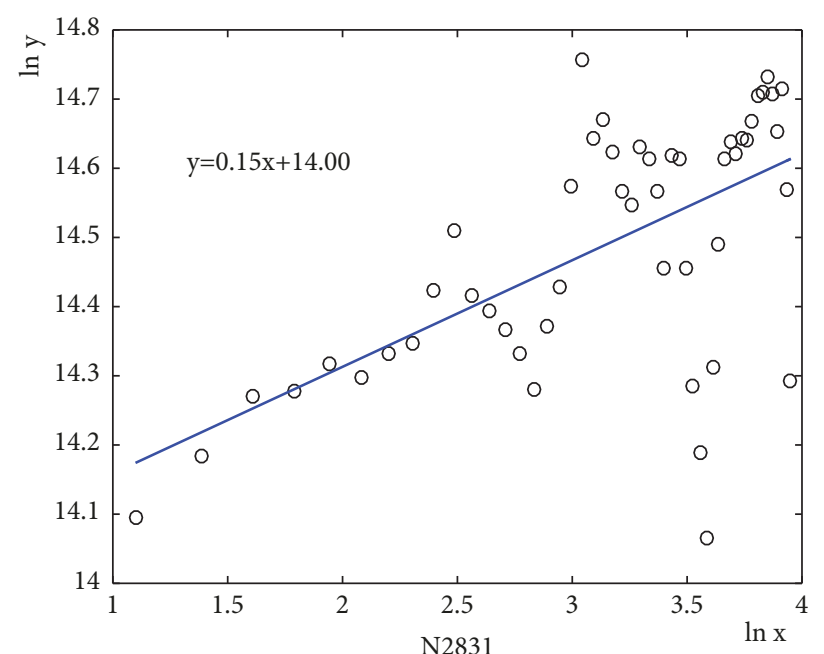

(a) The memory of original N2831 value

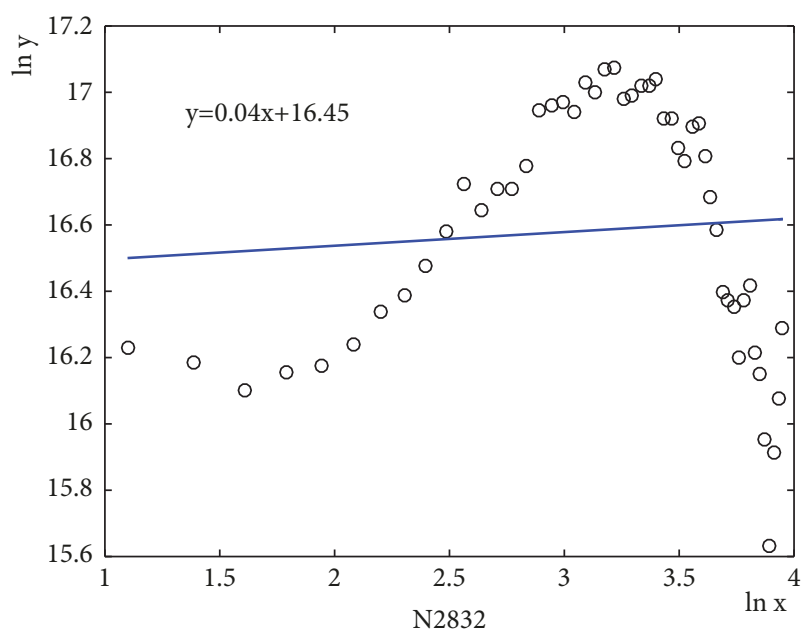

(c) The memory of original N2832 value

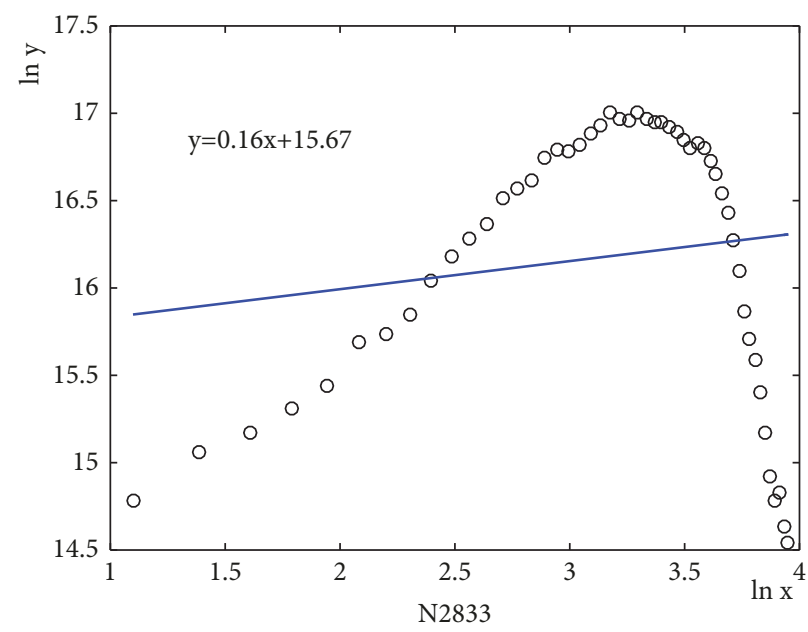

(e) The memory of original N2833 value

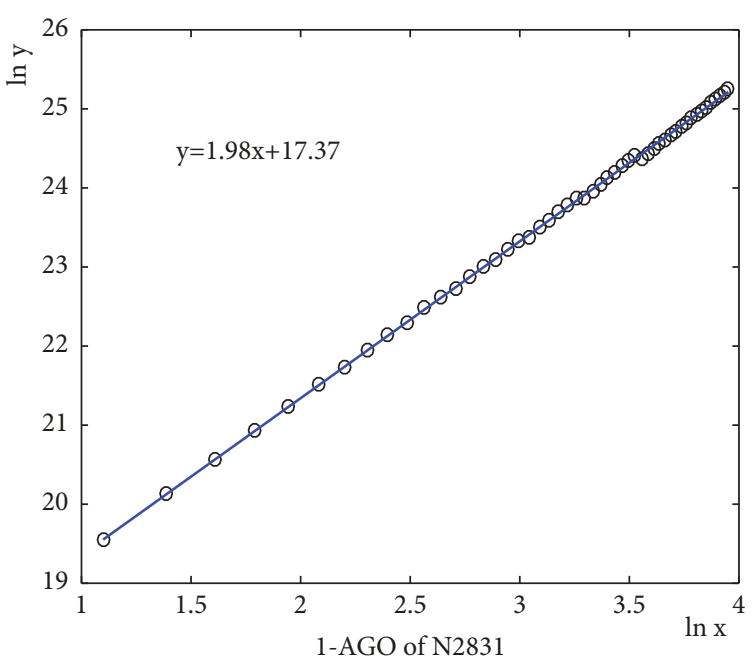

(b) The memory of 1-AGO N2831 value

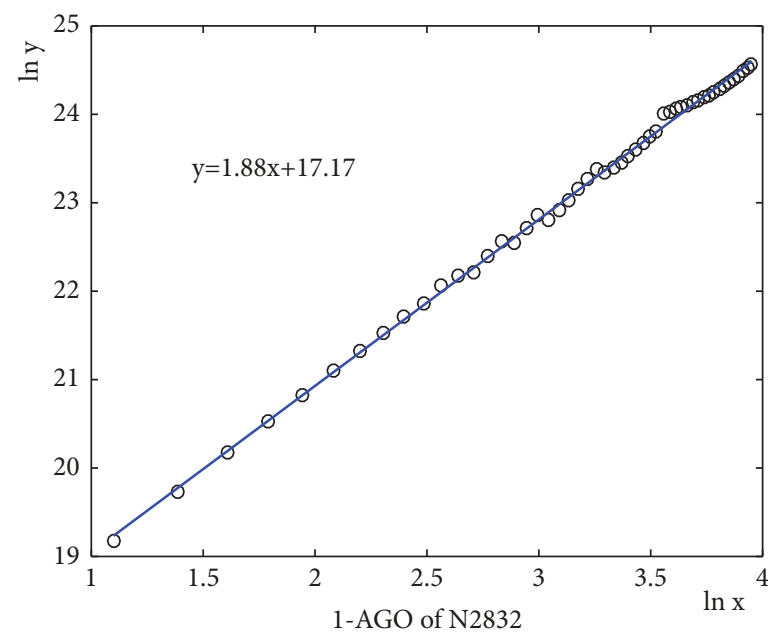

(d) The memory of 1-AGO N2832 value

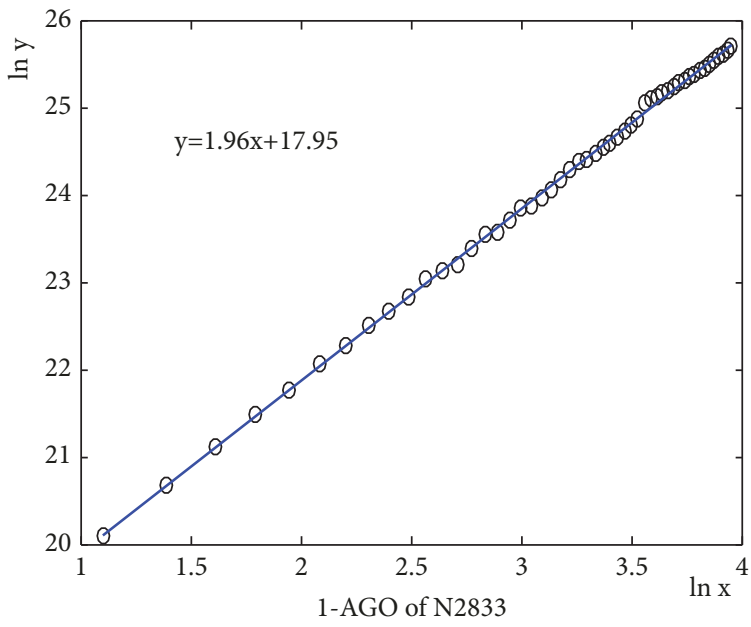

(f) The memory of 1-AGO N2833 value

FIGURE 2: The memory of original value and one-order accumulation value for three groups of data. 


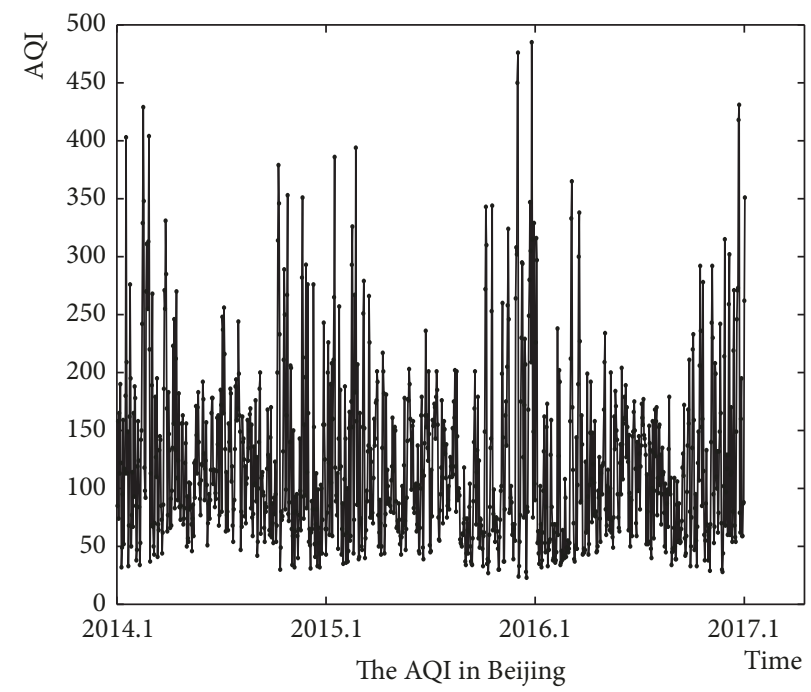

(a) The AQI in Beijing

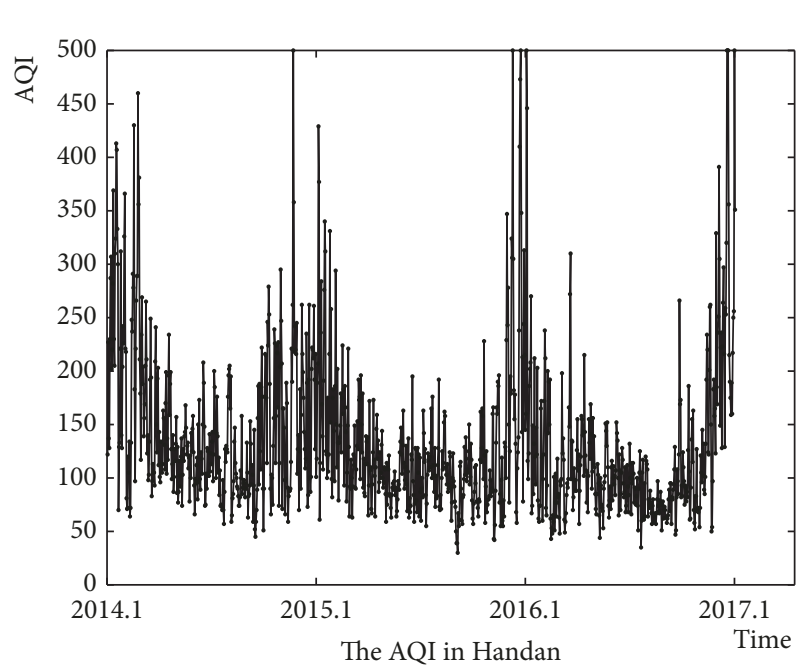

(c) The AQI in Handan

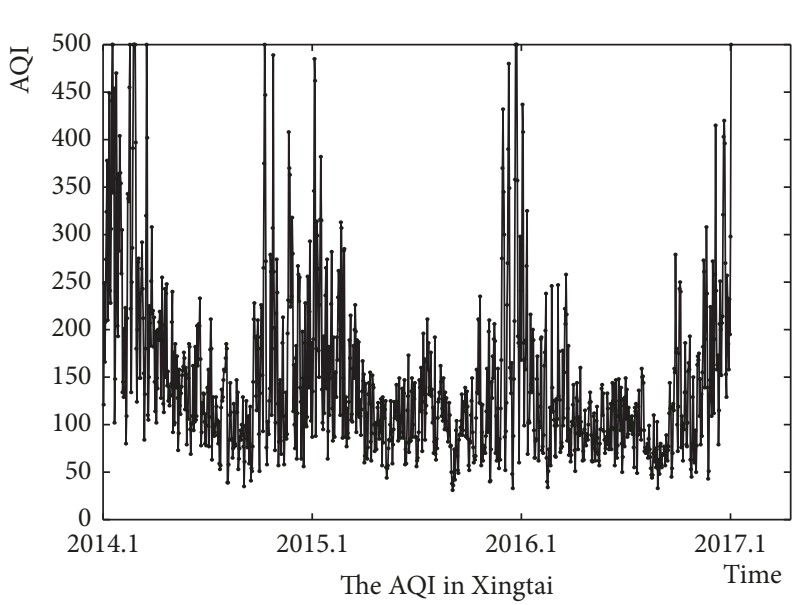

(e) The AQI in Xingtai

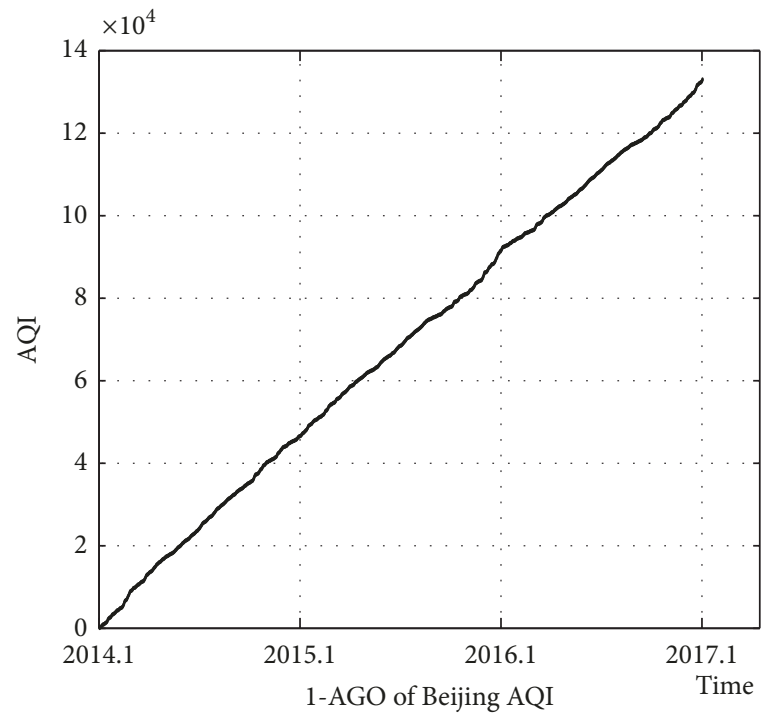

(b) The 1-AGO of Beijing AQI

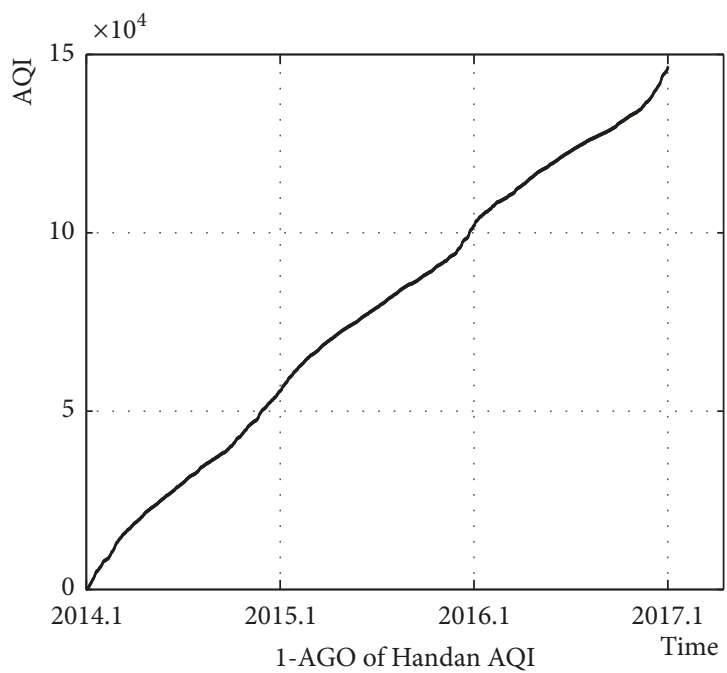

(d) The 1-AGO of Handan AQI

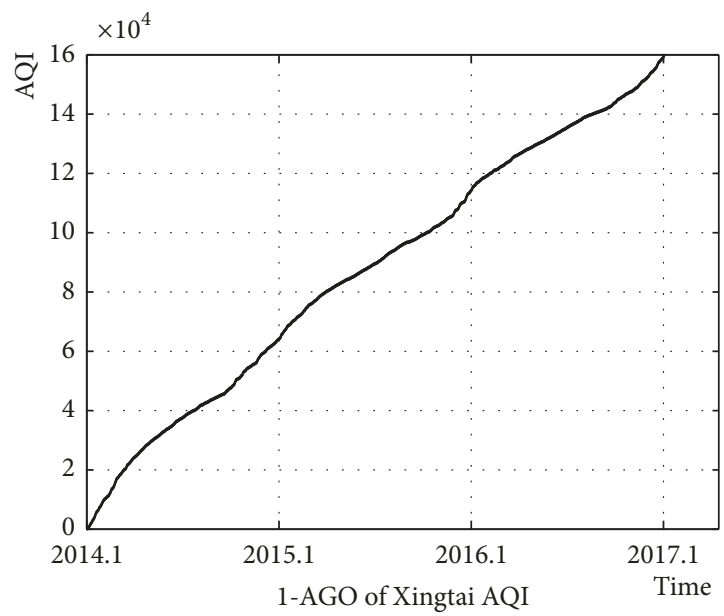

(f) The 1-AGO of Xingtai AQI

FIGURE 3: The original AQI value and one-order accumulation value of three cities. 


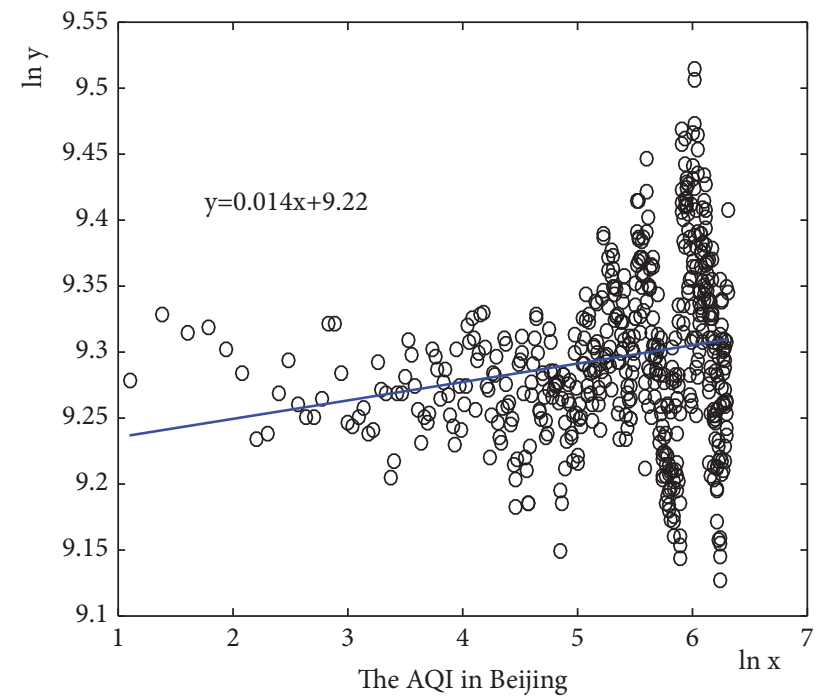

(a) The memory of original Beijing AQI

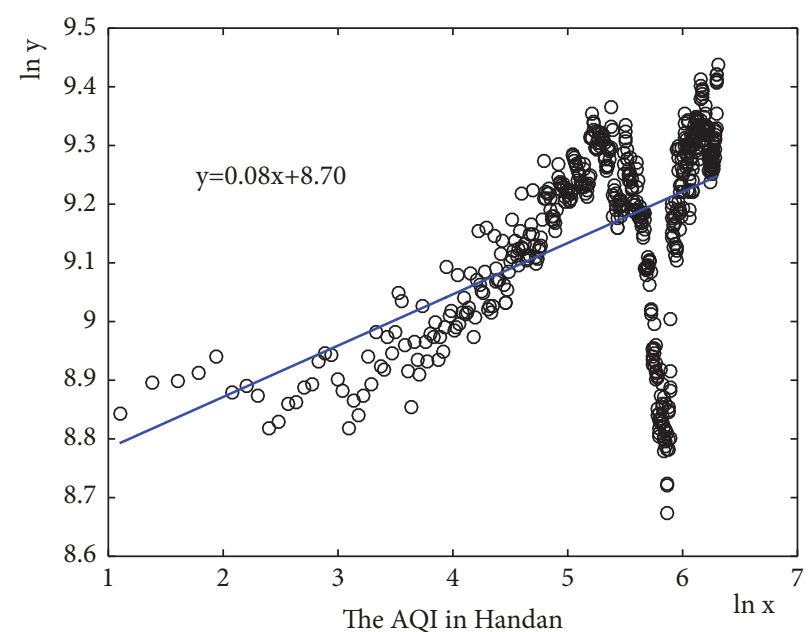

(c) The memory of original Handan AQI

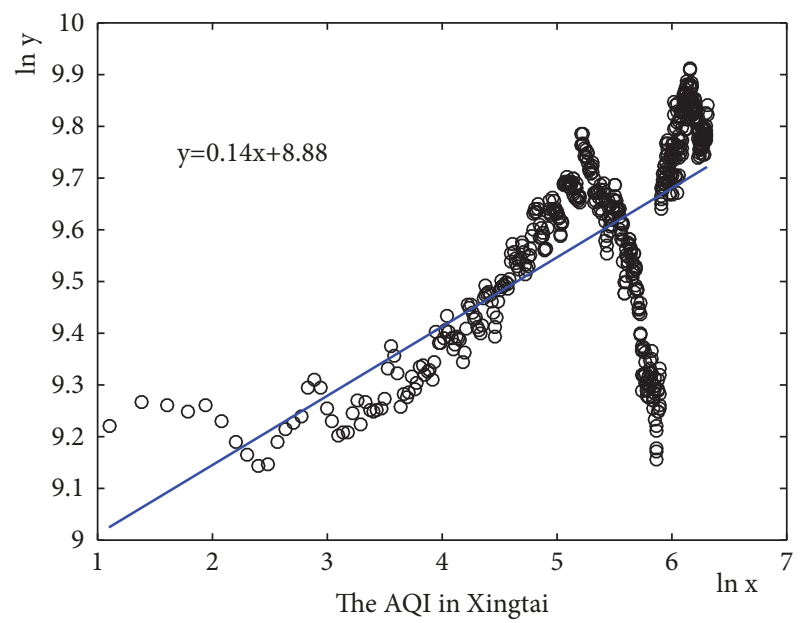

(e) The memory of original Xingtai AQI

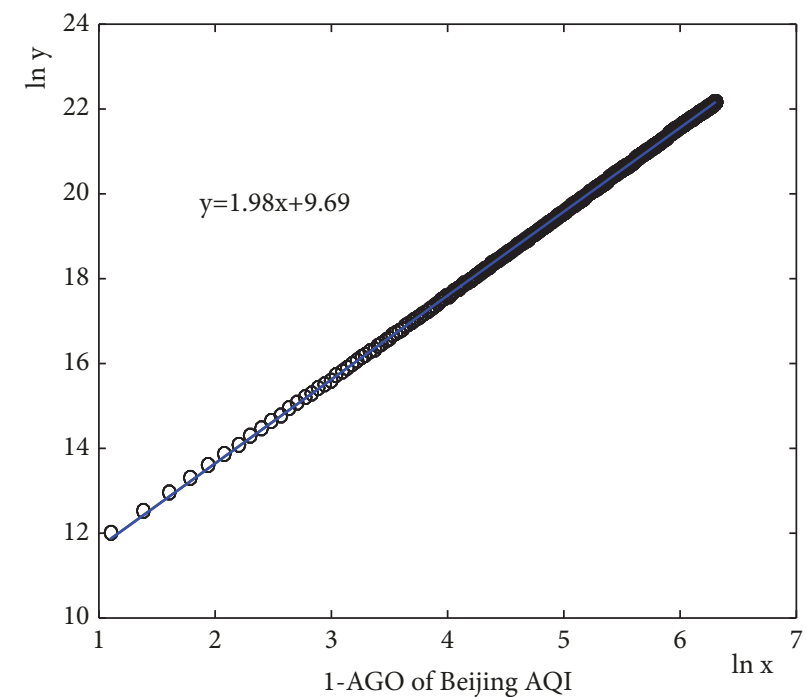

(b) The memory of 1-AGO Beijing AQI

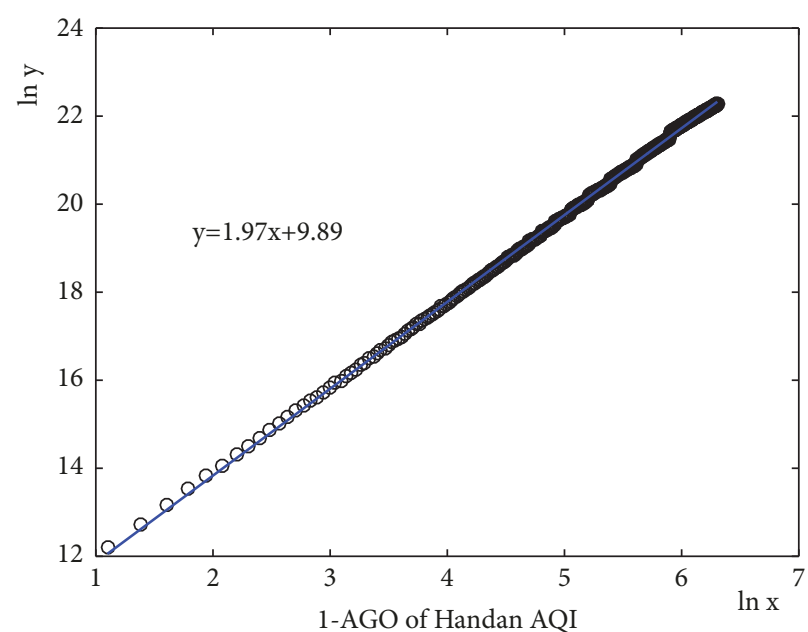

(d) The memory of 1-AGO Handan AQI

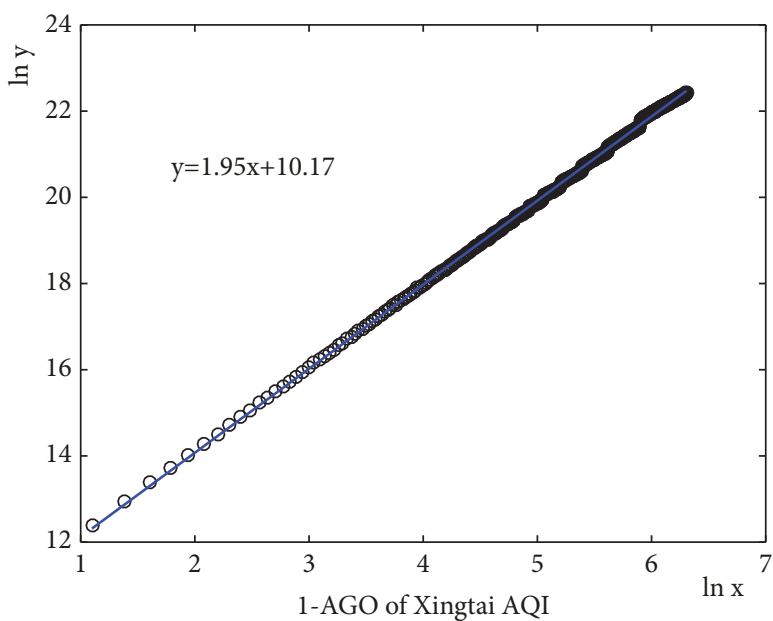

(f) The memory of 1-AGO Xingtai AQI

FIgURE 4: The memory of original AQI value and one-order accumulation value of three cities. 
TABLE 2: The AQI Hurst exponent value of three cities.

\begin{tabular}{lccc}
\hline & Beijing & Handan & Xingtai \\
\hline Original sequence & 0.007 & 0.04 & 0.07 \\
Accumulation sequence & 0.99 & 0.99 & 0.98 \\
\hline
\end{tabular}

TABle 3: The Hurst exponent value of two indexes.

\begin{tabular}{lcc}
\hline & Car production & Power generating capacity \\
\hline Original sequence & 0.20 & 0.34 \\
Accumulation sequence & 0.96 & 0.99 \\
\hline
\end{tabular}

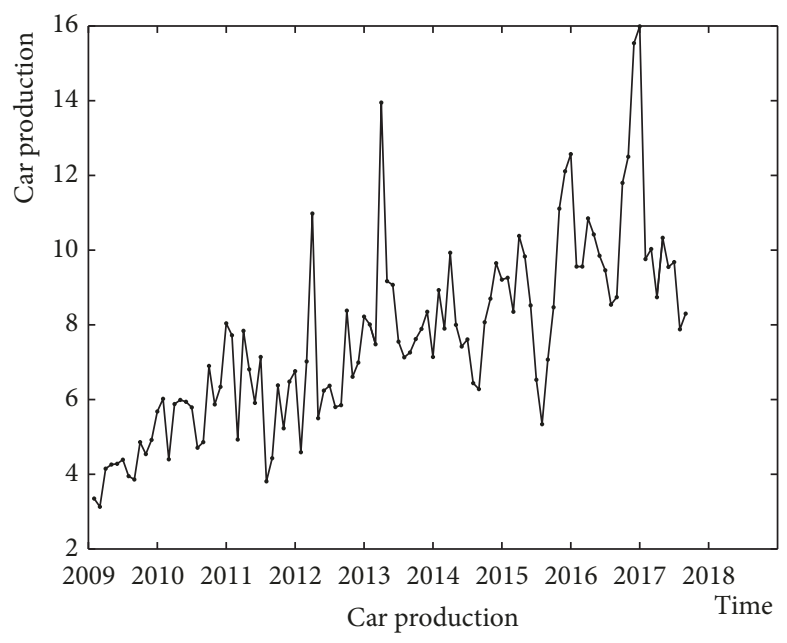

(a) The original car production

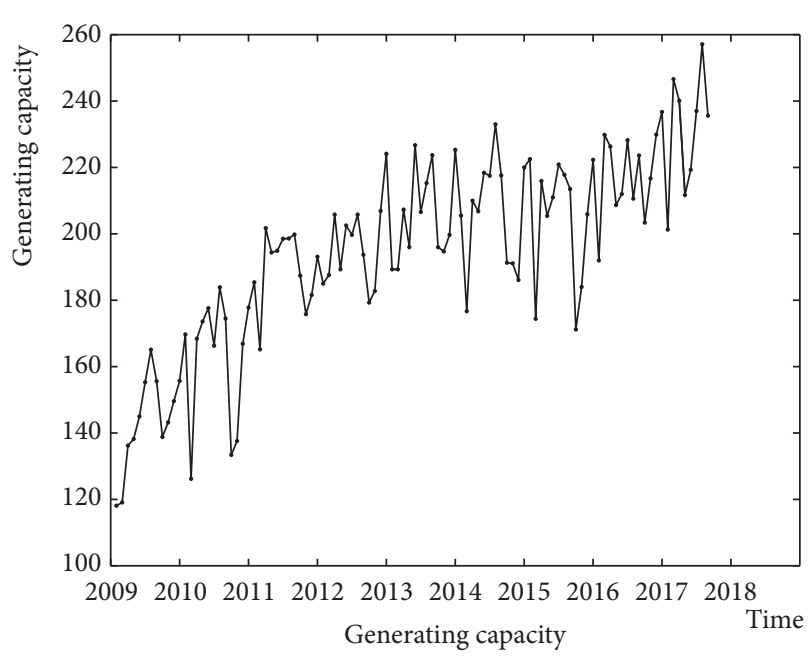

(c) The original power capacity

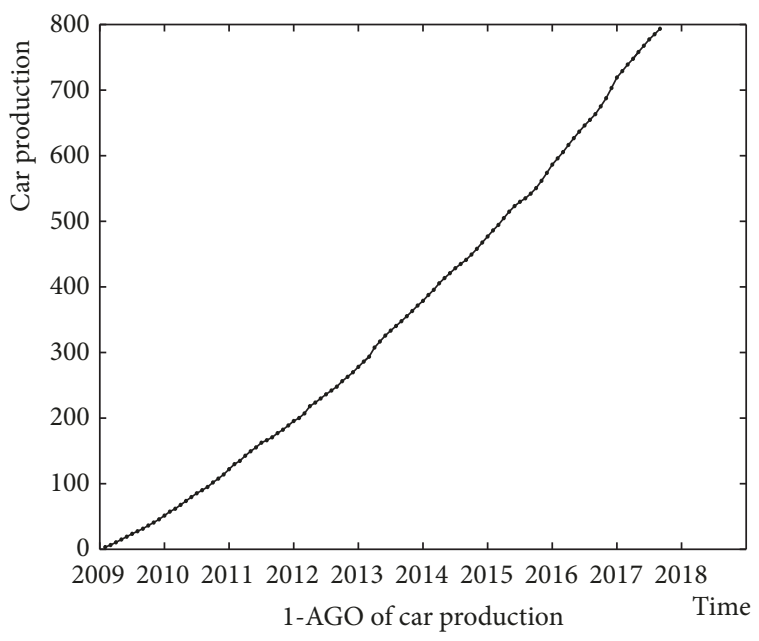

(b) The 1-AGO of car production

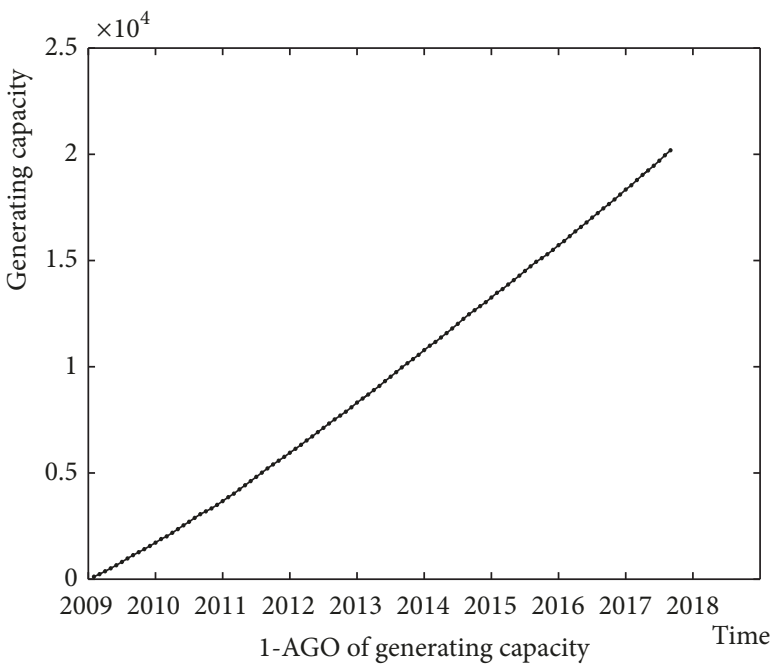

(d) The 1-AGO of power capacity

FIGURE 5: The original value and one order accumulation value for two indexes.

As seen in Table 3, the $H(2)$ values of the accumulation sequence are larger than those of the original time sequence for both indexes.

In Figure 6, it is noted that the points of the original value are scattered whereas those of the accumulation sequence are evenly distributed in a straight line. Therefore, the accumulation sequence yields superior persistence.

Actually, for the big size cases, the memory of sequence is enhanced by the 1-AGO. For the small size cases, the memory of sequence is also enhanced by the 1-AGO. 


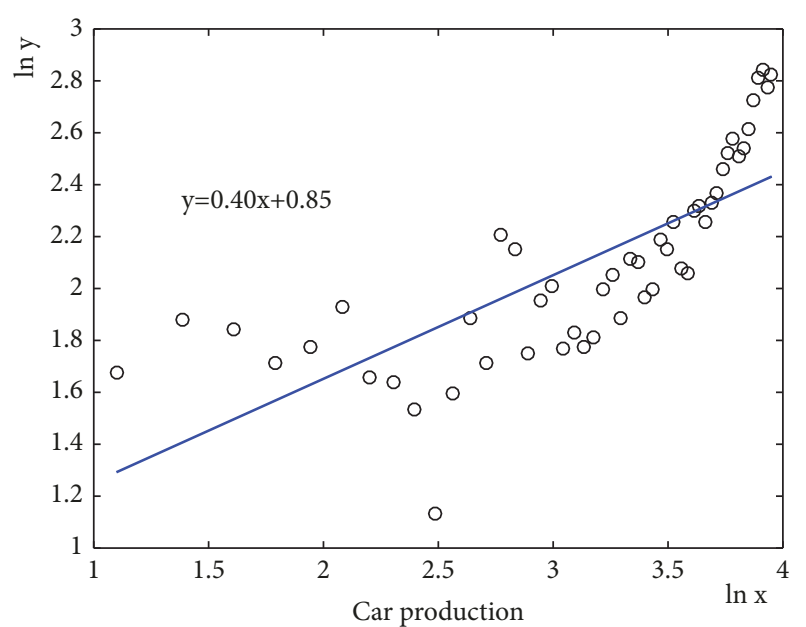

(a) The memory of original car production

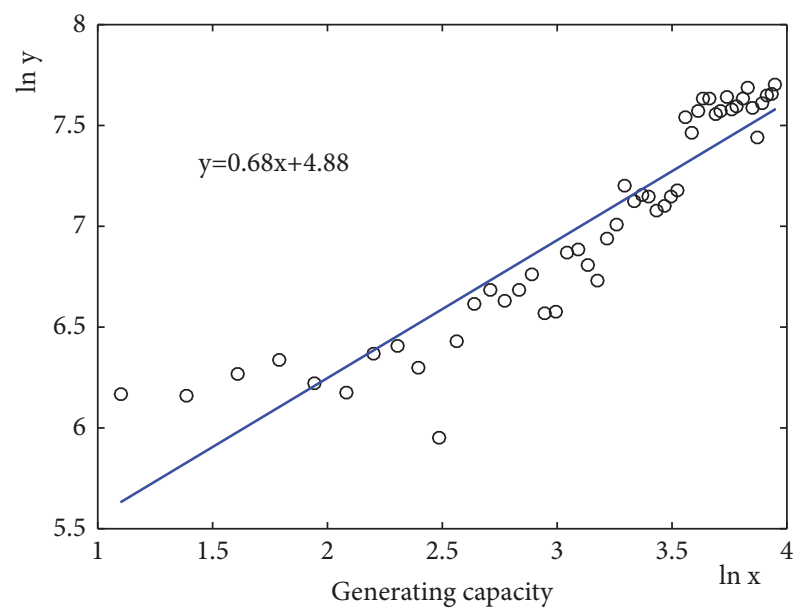

(c) The memory of power capacity

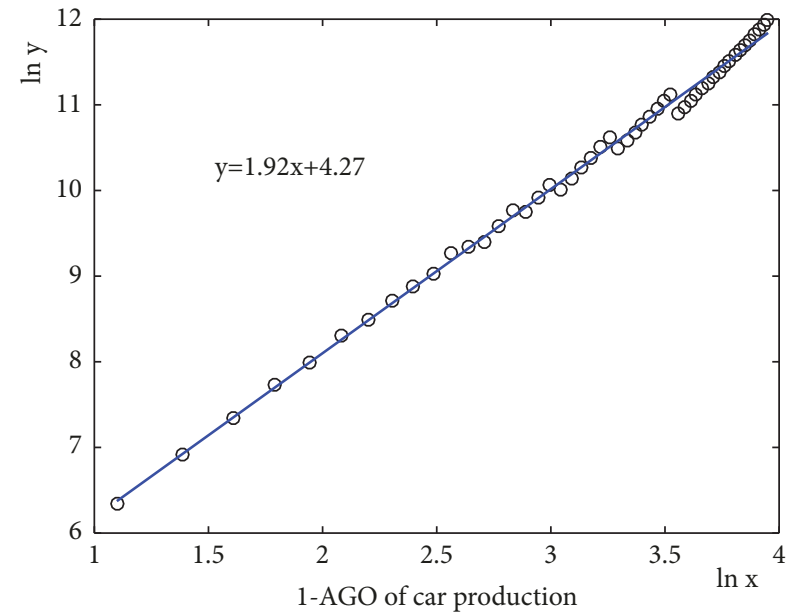

(b) The memory of l-AGO car production

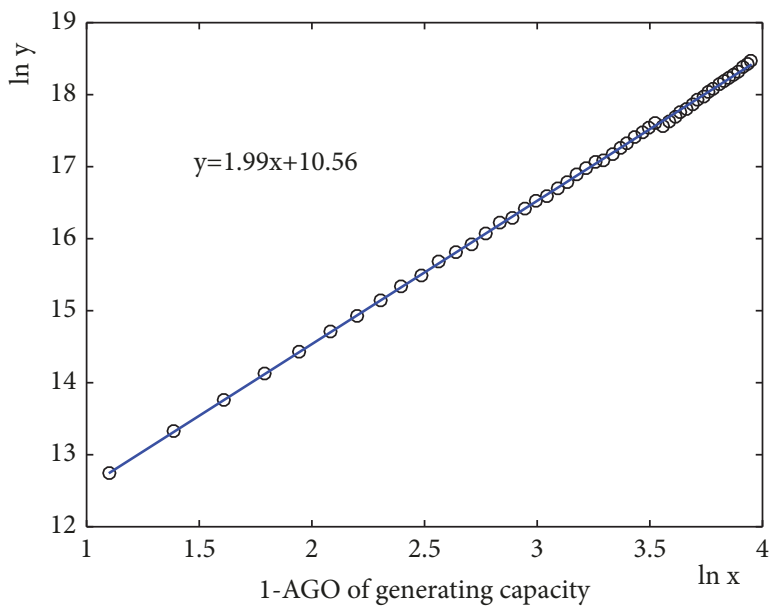

(d) The memory of 1-AGO power capacity

FIgURE 6: The memory of original value and one-order accumulation value for two indexes.

\section{Comparison of $\mathrm{GM}(1,1)$ Model and the Other Models}

As the basis of the grey forecasting theory, $\operatorname{GM}(1,1)$ is the first-order single variable grey forecasting model, and it has been widely investigated and studied by many scholars in theoretical and practical fields [24]. The steps of $\mathrm{GM}(1,1)$ are shown in the following.

Step 1. An original positive sequence is $X^{(0)}=\left\{x^{(0)}(1)\right.$, $\left.x^{(0)}(2), \cdots x^{(0)}(n)\right\}$. One-order accumulation sequence is $X^{(1)}=\left\{x^{(1)}(1), x^{(1)}(2), \cdots x^{(1)}(n)\right\}$.

Step 2. The $\mathrm{GM}(1,1)$ model is $x^{(0)}(k)+a z^{(1)}(k)=b, z^{(1)}(k)=$ $(1 / 2)\left(x^{(1)}(k)+x^{(1)}(k-1)\right), k=2,3, \cdots, n$.

Its whitenization equation is $d x^{(1)} / d t+a x^{(1)}=b \cdot a$ and $b$ are coefficients. $a$ is the developing coefficient, and $b$ is the grey input. $a$ and $b$ are obtained by the least-squares method as follows:

$$
\left[\begin{array}{l}
\widehat{a} \\
\widehat{b}
\end{array}\right]=\left(B^{T} B\right)^{-1} B^{T} Y
$$

where

$$
\begin{aligned}
& Y=\left[\begin{array}{c}
x^{(0)}(2) \\
x^{(0)}(3) \\
\vdots \\
x^{(0)}(n)
\end{array}\right], \\
& B=\left[\begin{array}{ccc}
-z^{(1)}(2) & 1 \\
-z^{(1)}(3) & 1 \\
\vdots & & \vdots \\
-z^{(1)}(n) & 1
\end{array}\right] \text {. }
\end{aligned}
$$

Step 3. The solution of $d x^{(1)} / d t+a x^{(1)}=b$ is $x^{(1)}(t+1)=$ $\left(x^{(0)}(1)-b / a\right) e^{-a t}+b / a$. According to $\hat{x}^{(1)}(1)=x^{(0)}(1), \hat{x}^{(1)}(t+$ $1)$ is obtained as $\widehat{x}^{(1)}(t+1)=\left(x^{(0)}(1)-\widehat{b} / \widehat{a}\right) e^{-a t}+\widehat{b} / \widehat{a}$.

Step 4. To obtain the predicted value of the data at time $(k+1)$, the forecasting sequence is $\widehat{X}^{(0)}=$ 
TABLE 4: The results for different models for M3C N1.

\begin{tabular}{lcccc}
\hline Data & GM $(1,1)$ & Winter & ARAMRA & AUTO-ANN \\
\hline 5379.75 & 5506.72 & 5406.43 & 5553.26 & 5453.28 \\
6158.68 & 6153.6 & 5875.96 & 6246.45 & 6003.49 \\
6876.58 & 6876.48 & 6345.48 & 7026.18 & 6587.93 \\
7851.91 & 7684.27 & 6815 & 7903.23 & 7206.76 \\
8407.84 & 8586.96 & 7284.53 & 8889.77 & 7860.01 \\
9156.01 & 9595.69 & 7754.05 & 9999.45 & 8547.55 \\
MAPE & 1.92 & 9.11 & 3.74 & 4.91 \\
\hline
\end{tabular}

$\left\{\hat{x}^{(0)}(1), \hat{x}^{(0)}(2), \cdots, \widehat{x}^{(0)}(n)\right\}$ and the inverse accumulating generation operation $\widehat{x}^{(0)}(k+1)=\widehat{x}^{(1)}(k+1)-\widehat{x}^{(1)}(k)$ is applied as follows: $\widehat{x}^{(0)}(t+1)=\left(x^{(0)}(1)-\widehat{b} / \widehat{a}\right)\left(1-e^{a}\right) e^{-a t}$.

$\mathrm{GM}(1,1)$ is one of the most common methods used for studying data sets characterized by small size. The above cases have big size; $\mathrm{GM}(1,1)$ is not the better model for above cases. Therefore, the series N1 (sample size is 14) from the M3 forecasting competition is selected as the evaluation data. The data is downloaded from the Internet site: http://www.insead.fr/facultyresearch/forecasting.

The memory of accumulation sequence is evaluated by comparing the traditional $\mathrm{GM}(1,1)$ model with the other models in this section. Therefore, mean absolute percentage error $\left(\mathrm{MAPE}=100 \%(1 / n) \sum_{k=1}^{n}\left|\left(x^{(0)}(k)-\widehat{x}^{(0)}(k)\right) / x^{(0)}(k)\right|\right)$ compares the actual values with the forecasting values. The last 6 observations are used to evaluate their accuracy. The forecasting results of the series N1 are listed in Table 4 and are plotted in Figure 7.

Winter model, ARAMRA, and AUTO-ANN are the most common methods used for studying data sets characterized by small size. In Table 4 , it indicated that the MAPE of $\operatorname{GM}(1,1)$ are smaller than that of other models. We can say that the $\operatorname{GM}(1,1)$ model is better than the others. The original time sequence always shows strong antipersistent behavior. It is difficult to dig out the information in the sequence. The AGO can strengthen the memory of the time sequence. Therefore, it plays a pivotal role to establish model. With the application of AGO in $\operatorname{GM}(1,1)$ model, the case imply that $\mathrm{GM}(1,1)$ model has higher forecasting performance.

\section{Conclusion}

For a time sequence, the current state is the result of a series of interrelated events. The development state has a longterm (short-term) memory. In general, the Hurst exponent of original time sequence is less than or close to 0.5 . In this situation, the time sequence always shows stronger antipersistent behavior; it means that the time sequence follows a random walk with mutability or volatility. As can be seen from the experimental cases, the Hurst exponent of one-order accumulation sequence was very close to 1 , the randomness of the time sequence was significantly weakened and the regularity was strengthened. By the 1-AGO, the memory of sequence is enhanced and the accumulation sequence yields

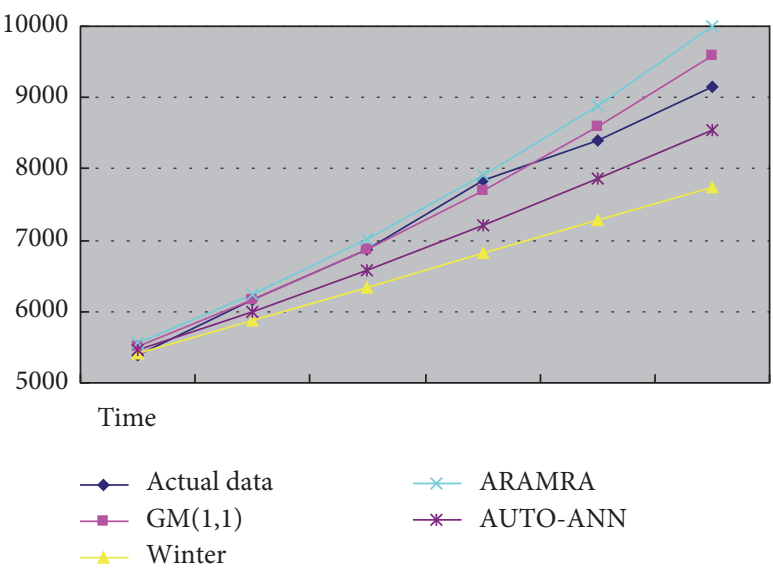

FIgURE 7: The predicted and true values for M3C N1.

superior persistence. The future trend can be predicted based on the present state.

It is worthwhile to use 1-AGO in grey prediction. On one hand, the randomness of the original sequence is weakened by 1-AGO. On the other hand, grey accumulation generation sequence can provide additional information for modeling and enable the data to construction a more appropriate model. Because the Hurst exponent of one order accumulation sequence was very close to the maximum (i.e., 1), for the grey forecasting model, the accumulation-order number cannot be more than 1 in practical applications.

Three cases are discussed to demonstrate the memory of grey AGO. In the future, more cases are needed to be discussed to demonstrate the memory. All values in this paper are positive, so the accumulation frequency is always increasing. In this case, the Hurst Exponent is close to 1. Of course, this property may change when the original time sequence contains negative values. In the future, more cases with negative values are needed to be discussed.

\section{Conflicts of Interest}

All authors declare that they have no conflicts of interest.

\section{Acknowledgments}

The relevant researches in this paper are supported by the National Natural Science Foundation of China (Nos. 
71871084, 71401051), the Excellent Young Scientist Foundation of Hebei Education Department (No. SLRC2019001), and the project of high-level talent in Hebei province.

\section{References}

[1] Q. Wang, L. Liu, S. Wang, J.-Z. Wang, and M. Liu, "Predicting Beijing's tertiary industry with an improved grey model," Applied Soft Computing, vol. 57, pp. 482-494, 2017.

[2] F. Shaikh, Q. Ji, P. H. Shaikh, N. H. Mirjat, and M. A. Uqaili, "Forecasting China's natural gas demand based on optimised nonlinear grey models," Energy, vol. 140, pp. 941-951, 2017.

[3] S. Ene and N. Öztürk, "Grey modelling based forecasting system for return flow of end-of-life vehicles," Technological Forecasting \& Social Change, vol. 115, pp. 155-166, 2017.

[4] B. Zeng, C. Luo, C. Li, and S. Liu, "A novel multi-variable grey forecasting model and its application in forecasting the amount of motor vehicles in Beijing," Computers \& Industrial Engineering, vol. 101, pp. 479-489, 2016.

[5] B. Zeng and C. Li, "Forecasting the natural gas demand in China using a self-adapting intelligent grey model," Energy, vol. 112, pp. 810-825, 2016.

[6] Z.-X. Wang, Q. Li, and L.-L. Pei, "Grey forecasting method of quarterly hydropower production in China based on a data grouping approach," Applied Mathematical Modelling, vol. 51, pp. 302-316, 2017.

[7] Z.-X. Wang and D.-J. Ye, "Forecasting Chinese carbon emissions from fossil energy consumption using non-linear grey multivariable models," Journal of Cleaner Production, vol. 142, pp. 600-612, 2017.

[8] J. Wang, K. W. Hipel, and Y. Dang, "An improved grey dynamic trend incidence model with application to factors causing smog weather," Expert Systems with Applications, vol. 87, pp. 240-251, 2017.

[9] N. Xu, Y. Dang, and Y. Gong, "Novel grey prediction model with nonlinear optimized time response method for forecasting of electricity consumption in China," Energy, vol. 118, pp. 473-480, 2017.

[10] L. Wu, S. Liu, D. Chen, L. Yao, and W. Cui, "Using gray model with fractional order accumulation to predict gas emission," Natural Hazards, vol. 71, no. 3, pp. 2231-2236, 2014.

[11] C.-J. Chang, J.-Y. Lin, and P. Jin, "A grey modeling procedure based on the data smoothing index for short-term manufacturing demand forecast," Computational and Mathematical Organization Theory, vol. 23, no. 3, pp. 409-422, 2017.

[12] K. L. Wen, Grey prediction theory and application, Open Tech Company, Taipei, Taiwan, 2002.

[13] X. Xiao, J. Yang, S. Mao, and J. Wen, "An improved seasonal rolling grey forecasting model using a cycle truncation accumulated generating operation for traffic flow," Applied Mathematical Modelling, vol. 51, pp. 386-404, 2017.

[14] L. Wu, S. Liu, L. Yao, R. Xu, and X. Lei, "Using fractional order accumulation to reduce errors from inverse accumulated generating operator of grey model," Soft Computing, vol. 19, no. 2, pp. 483-488, 2014.

[15] T. Di Matteo, T. Aste, and M. M. Dacorogna, "Scaling behaviors in differently developed markets," Physica A: Statistical Mechanics and its Applications, vol. 324, no. 1-2, pp. 183-188, 2003.

[16] J. P. Ramos-Requena, J. E. Trinidad-Segovia, and M. A. SánchezGranero, "Introducing Hurst exponent in pair trading," Physica
A: Statistical Mechanics and its Applications, vol. 488, pp. 39-45, 2017.

[17] L. Salim and S. Amir, "Accurate classification of seizure and seizure-free intervals of intracranial EEG signals from epileptic patients," IEEE Transactions on Instrumentation, vol. 68, no. 3, pp. 791-796, 2019.

[18] S. Lahmiri, "An accurate system to distinguish between normal and abnormal electroencephalogram records with epileptic seizure free intervals," Biomedical Signal Processing and Control, vol. 40, pp. 312-317, 2018.

[19] L. Salim, "Glioma detection based on multi-fractal features of segmented brain MRI by particle swarm optimization techniques," Biomedical Signal Processing and Control, vol. 31, pp. 148-155, 2017.

[20] T. Blachowicz, A. Ehrmann, and K. Domino, "Statistical analysis of digital images of periodic fibrous structures using generalized Hurst exponent distributions," Physica A: Statistical Mechanics and its Applications, vol. 452, pp. 167-177, 2016.

[21] M. Ausloos, "Generalized Hurst exponent and multifractal function of original and translated texts mapped into frequency and length time series," Physical Review E: Statistical, Nonlinear, and Soft Matter Physics, vol. 86, no. 3, Article ID 031108, 2012.

[22] C. Dou, X. Wei, and J. Lin, "Fault diagnosis of gearboxes using nonlinearity and determinism by generalized hurst exponents of shuffle and surrogate data," Entropy, vol. 20, no. 5, p. 364, 2018.

[23] W. Wang, Long Memory Characteristics And Prediction of Financial Time Series, Nankai University Press, 2018.

[24] B. Zeng, H. Duan, and Y. Zhou, "A new multivariable grey prediction model with structure compatibility," Applied Mathematical Modelling: Simulation and Computation for Engineering and Environmental Systems, vol. 75, pp. 385-397, 2019. 


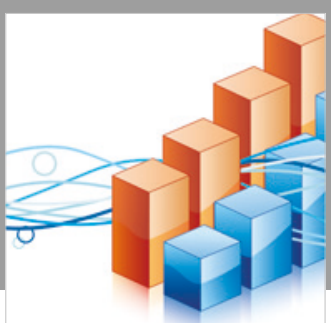

Advances in

Operations Research

\section{-n-m}
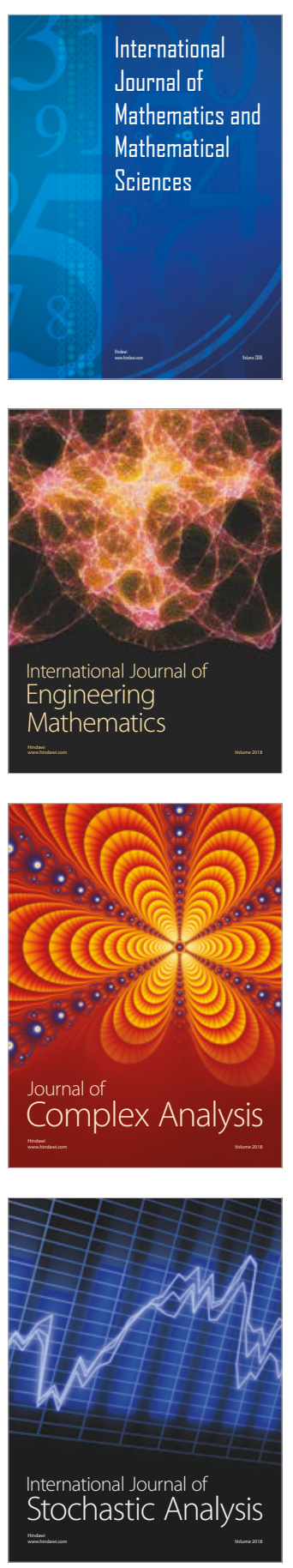
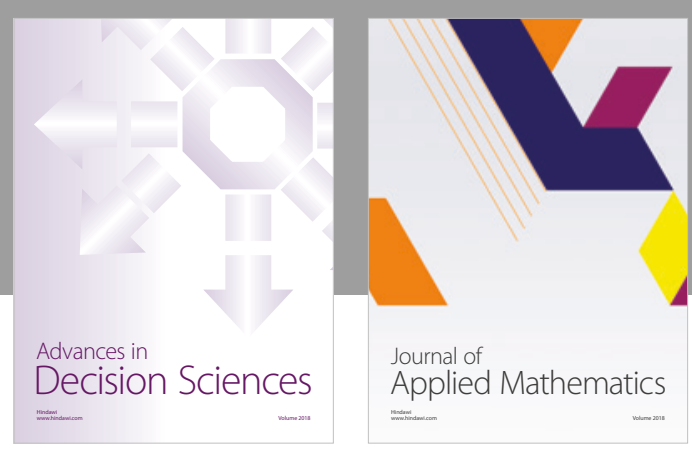

Journal of

Applied Mathematics
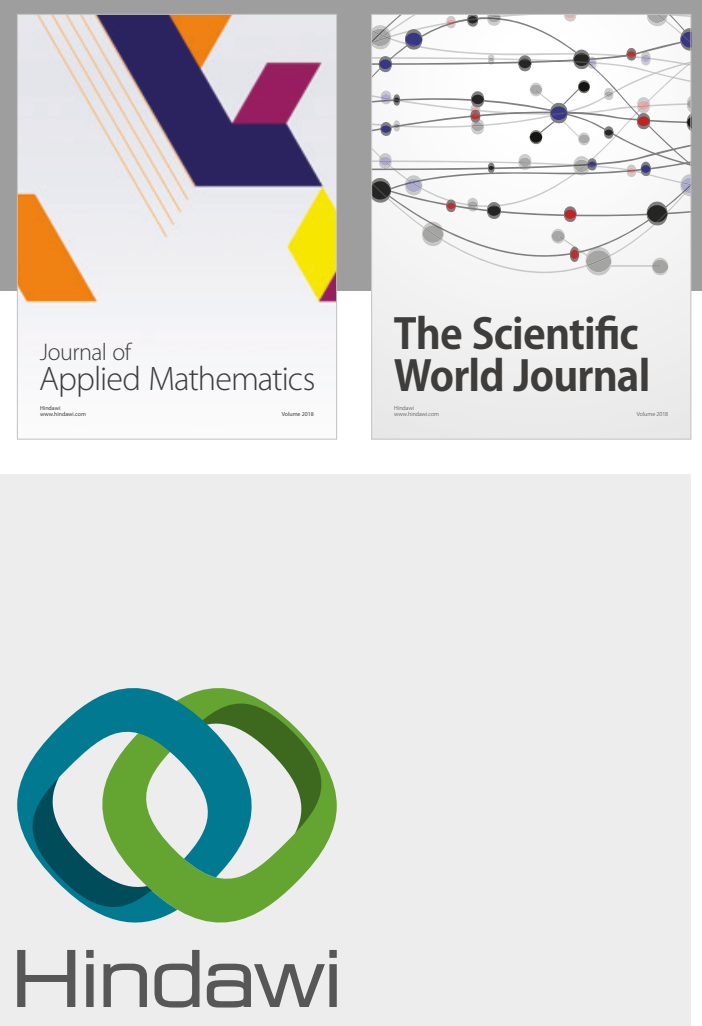

Submit your manuscripts at

www.hindawi.com

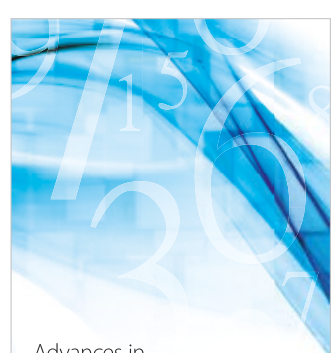

Advances in
Numerical Analysis
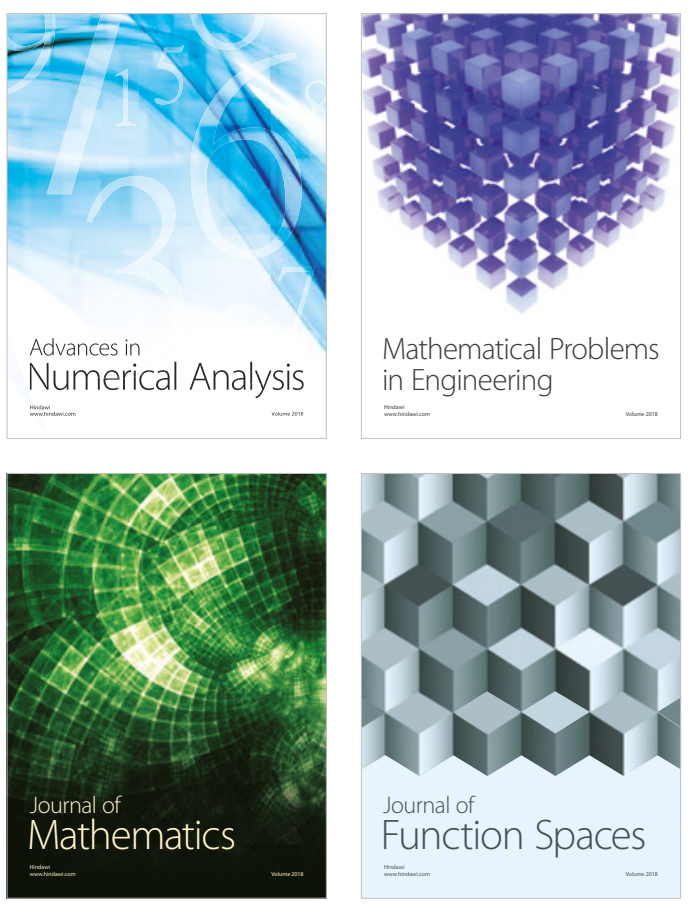

Mathematical Problems in Engineering

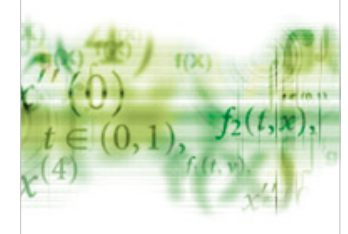

International Journal of

Differential Equations

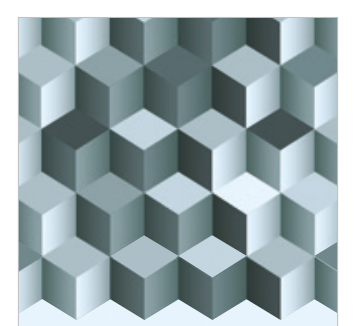

Journal of

Function Spaces
The Scientific

World Journal

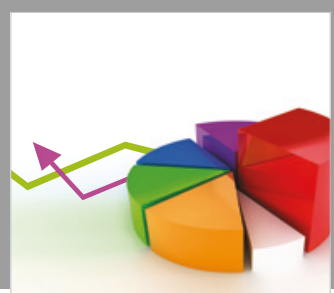

Journal of

Probability and Statistics
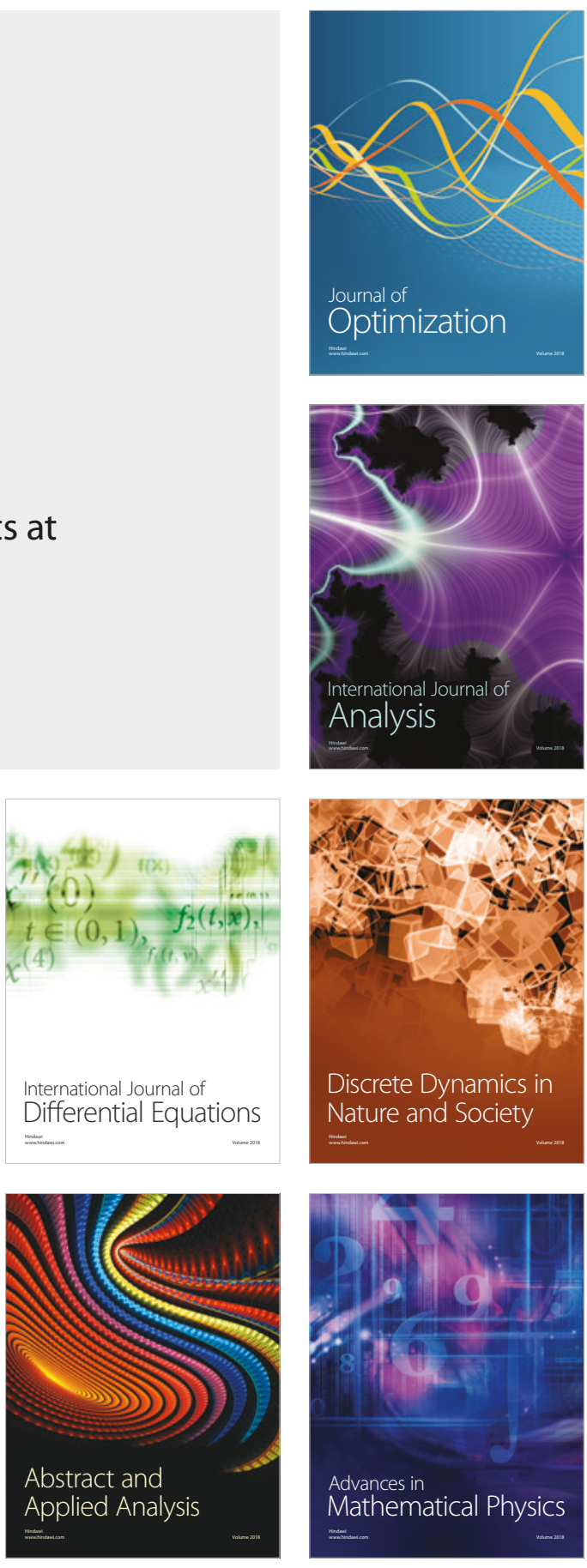